\title{
Conhecimentos para ensinar área de figuras planas explicitados por futuros professores
}

\author{
Angélica da Fontoura Garcia Silva
}

Helenara Regina Sampaio Figueiredo

\section{Resumo}

Este artigo tem a finalidade de investigar duas categorias do conhecimento profissional docente - o conhecimento do conteúdo comum e o especializado - de um grupo de futuros professores sobre o conceito de área de figuras planas. O estudo foi realizado em uma universidade particular do Paraná e contou com a participação de 25 estudantes que lecionarão matemática para os Anos Iniciais. A coleta de dados envolveu a aplicação de um questionário, apresentado a eles em uma aula da disciplina, que discute os fundamentos e as metodologias para o ensino da Matemática nos Anos Iniciais. Esta investigação apoia-se tanto em estudos que discutem processos de ensino e aprendizagem de área como nos pesquisadores que tratam do conhecimento profissional docente. A análise das informações obtidas indicou lacunas, tanto no conhecimento comum como no especializado a respeito de área e do perímetro. Além disso, observou-se a necessidade no decorrer das aulas da disciplina introduzir a temática a partir da ideia de medida e promover de reflexões acerca de resultados de pesquisa e sobre diferentes estratégias e metodologias de relativas ao ensino de cálculo de área de figuras planas. Com base neste e em outros estudos nota-se a necessidade de um enfoque mais amplo do conceito de área de figuras plana, a partir da compreensão da ideia de unidade de medida e discussão sobre as diferentes estratégias de seu cálculo tanto em cursos de formação inicial como de formação continuada.

Palavras-chave: Formação inicial. Ensino da Matemática. Área. Figuras planas. Conhecimento especializado. 


\title{
Learning how to teach mathematics: knowledge for teaching area of plane figures explicited by future teachers
}

\author{
Helenara Regina Sampaio Figueiredo \\ Angelica da Fontoura Garcia Silva
}

\section{Abstract}

This article aims to investigate two categories regarding teaching professional knowledge - knowledge of common and the specialized content - of a group of future teachers on the concept of flat figure area. This study was carried out at a private university in Paraná state with the participation of 25 students who will teach mathematics for the elementary school initial years. The data collection involved the application of a questionnaire that was shown to them during a math class, which discusses the fundamentals and methodologies for teaching mathematics in initial school years. This research is based both on studies that discuss processes of teaching and learning area and on researchers who deal with teaching professional knowledge. The analysis of the data has indicated gaps in both common and specialized knowledge regarding area and perimeter. In addition, during the discipline classes, it was observed the need to introduce the theme from the idea of measurement and promote reflections on research results and on different strategies and methodologies relating to teaching calculation of flat figure areas. Based on this and other studies, the need for a broader approach on the concept of flat figure area is noted, from the understanding of the idea of measurement unit and discussion on the different strategies of its calculation both in initial formation courses and continuing formation.

Keywords: Initial formation. Mathematics teaching. Area. Plane figures. Specialized knowledge. 


\section{Introdução}

Os documentos oficiais, como as orientações das Diretrizes Curriculares Nacionais do Curso de Pedagogia (BRASIL, 2006), apresentam, entre os princípios formativos gerais para o Curso, a necessidade de que a formação inicial do pedagogo seja consistente. Todavia a carga horária dos cursos de Pedagogia dedicada ao ensino parece não ser suficiente para garantir a qualidade exigida para essa formação. A esse respeito Curi (2006), assevera que a formação matemática oferecida pelos cursos de Licenciatura em Pedagogia no Brasil não chega a 4\%. Tal fato é confirmado em pesquisas mais recentes. Gatti (2009), por exemplo, revela que, nesses cursos, o foco, na maioria das vezes, é centrado nas discussões mais gerais a respeito dos pressupostos envolvidos nos processos de ensino, sem relacioná-los, via de regra, ao conteúdo específico das disciplinas. Esses e outros entraves observados na formação inicial do professor parecem estar repercutindo negativamente na atuação do professor.

Mandarino (2013), por exemplo, ao pesquisar as aulas de 116 professores que lecionavam para os anos iniciais, observou erros conceituais envolvendo as propriedades de figuras geométricas, nomenclaturas e classificações e considerou o campo da geometria como o mais problemático. Dentro dessa perspectiva, ao considerar que o tempo destinado as discussões específicas sobre o ensino da Matemática são restritas nos cursos de Pedagogia observamos a relevância de analisar os conhecimentos prévios evidenciados por alunos desse curso em questão a respeito de área de figuras planas a fim de refletir sobre propostas de ensino dessa temática. Neste estudo, apoiados em Ball, Thames e Phelps (2008) nos propusemos a investigar duas categorias do conhecimento profissional docente, sobretudo o conhecimento do conteúdo comum e o especializado de um grupo de futuros professores sobre o conceito de área de figuras planas a partir da análise das respostas dadas a um questionário.

\section{Relevância e Fundamentação teórica}

Consideramos, assim como Clements e Stephan (2004), que a compreensão do conceito de área é complexa, uma vez que envolve diversas ideias matemáticas, como a compreensão do significado da unidade de medida, do cálculo da área por meio da reunião de figuras, da equivalência de áreas, da composição e decomposição de figuras. Todavia tais ideias não são triviais, uma vez que pesquisas apontam haver limitações na compreensão da unidade de medida e decomposição mesmo por alunos concluintes do Ensino Fundamental. Estudos internacionais, como os de Kamii e Kysh (2006), por exemplo, ao analisarem resultados de avaliações, observam que o quadrado unitário não é considerado pelos alunos investigados como a unidade de medida de áreas e, via de regra, ele não é utilizado para construir decomposições de figuras geométricas simples. 
Em âmbito nacional, estudos, como os de Garcia Silva, Galvão e Campos (2013) e o de Sampaio Figueiredo (2015), analisaram o conhecimento de futuros professores e de professores experientes. Garcia Silva, Galvão e Campos (2013) verificaram que professores que lecionam Matemática para os anos iniciais tinham repertório limitado de conhecimentos sobre o processo de cálculo de área uma vez que ficou evidente o foco na utilização da contagem e compensação de quadradinhos. O estudo constatou que nenhum dos professores investigado calculou a área da figura, analisando a figura como um todo ou até mesmo a possibilidade de decompô-la em triângulos ou retângulos.

Concernente a formação inicial observamos que futuros professores também encontram dificuldades relacionadas a essa temática. Na investigação de Sampaio Figueiredo (2015), por exemplo, em que se propôs que 47 licenciandos de um curso de Pedagogia resolvessem 14 atividades semelhantes à Prova Brasil pudemos observar limitações no conhecimento relacionada tanto ao tema "Espaço e Forma" como em "Grandezas e Medidas". Quanto aos conhecimentos sobre área de figuras planas, a autora observou que houve uma insciência grande de equívocos, especialmente pelo fato de que esses futuros professores confundiram o conceito de perímetro com o de área. Além disso, a autora observou que a fórmula da área de formato retangular era conhecida e foi aplicada pela maioria dos licenciandos, todavia muitos desses participantes equivocaram-se ao calcular a multiplicação. Nesse contexto, consideramos ser importante aprofundarmos um pouco mais sobre os conhecimentos prévios a respeito de ideias básicas relativas ao conceito de área de figuras planas explicitadas por um grupo de alunos de um curso de pedagogia a fim de refletir sobre possíveis propostas a serem desenvolvidas na formação inicial

Para elaborar o questionário e analisar seus resultados desta pesquisa, levamos em conta os pressupostos apresentados no estudo de Ball, Thames e Phelps (2008) e Tardif (2000). Analisaremos categorias de conhecimento para o ensino estabelecidas por esses autores, fundamentados nos estudos de Shulman (1986). Eles ampliaram a categorização desse último autor para o ensino da matemática em: (i) conhecimento do conteúdo (comum/horizontal/especializado); (ii) conhecimento pedagógico do conteúdo (do conteúdo e dos estudantes/ do conteúdo e do ensino/ conhecimento curricular).

Neste estudo, analisaremos questões relacionadas ao (i) conhecimento comum do conteúdo e (ii) conhecimento especializado do conteúdo. Para Ball, Thames e Phelps (2008), essa categoria de conhecimento comum do conteúdo (i) refere-se à capacidade do professor de, além de perceber os erros, também analisar e identificar prováveis causas desses erros e apresentar aos alunos esclarecimentos precisos e respostas convincentes do ponto de vista da matemática, que os ajude a enfrentar e superar suas dificuldades. O conhecimento especializado do conteúdo (ii) refere-se às habilidades necessárias à proposição de atividades 
pedagógicas que favoreçam a percepção de existência de outras estratégias e resoluções consideradas corretas (ou incorretas) do ponto de vista da Matemática.

Além disso, inspirados em Tardif (2000) procuramos investigar a natureza dos conhecimentos dos professores. $\mathrm{O}$ autor discute a diversidade dos saberes docentes os quais, segundo Tardif (2000) provém de diversas fontes, afirma ainda que os futuros professores, antes mesmo de ministrarem suas aulas, experimentaram "lições" no seu futuro local de trabalho, ou seja, esse profissional, mesmo antes de escolher o ofício docente, ficou pelo menos 12 anos na escola e vivenciou sua rotina e assim, considera essa uma primeira dimensão formadora. Nesse contexto, procuraremos investigar também as experiências anteriores dos participantes relacionadas a aprendizagem de área de figuras planas.

\section{Sobre a metodologia de pesquisa}

Esta investigação, de natureza qualitativa, foi desenvolvida por meio da aplicação de um questionário a 25 licenciandos em Pedagogia de uma universidade particular na região norte do estado do Paraná. As perguntas visaram analisar a formação e a compreensão dos participantes relativos a aspectos ligados ao conceito de área. É importante destacar que, de acordo com os participantes deste estudo, anteriormente a realização desta pesquisa eles não haviam estudado ou discutido questões que envolvessem esses assuntos, informação essa confirmada com o professor da turma.

Para analisar a formação e vivencias anteriores dos futuros professores, perguntamos (1) se eles já haviam lecionado e em que modalidade de ensino. Questionamos também sobre as (2) lembranças que eles tinham sobre o ensino de área e perímetro na Educação Básica e no ensino superior. Quanto às experiências com o ensino do tema, perguntamos aos futuros professores (3) se já haviam ensinado esse conteúdo e solicitamos que descrevessem a experiência. Para identificar o conhecimento a respeito do ensino do conteúdo, como descrito por Ball, Thames e Phelps (2008), perguntamos também aos futuros professores (4) se, quando estivessem lecionando para o $5^{\circ}$ ano do Ensino Fundamental, um de seus alunos perguntasse o que é área de uma figura, o que eles responderiam.

Para identificar o conhecimento comum do conteúdo analisamos as estratégias utilizadas pelos participantes na determinação da área de figuras planas desenhadas em malha quadriculadas (5) conforme o apresentado na Figura 3: 
Figura 3 - Figuras apresentadas na Questão que buscava determinar área em malha quadriculada

(A)

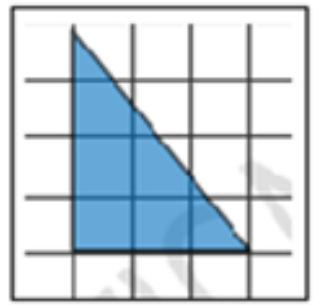

(B)

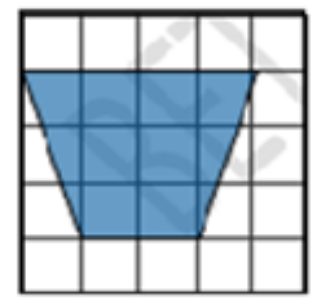

(C)

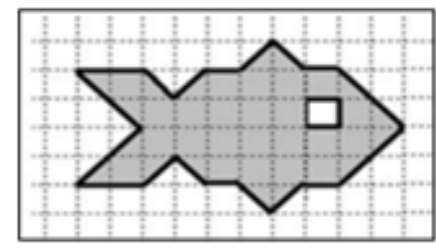

Fonte: Figura apresentada no questionário, inspirada na investigação de Pessoa (2010).

Observamos que duas dessas figuras são poligonais (A e B) e para elas a área pode ser calculada por meio da contagem ou pelo uso da fórmula. A figura $\mathrm{C}$ não é poligonal, mas o cálculo da área pode ser realizado pela (re)composição da imagem ou também pela contagem, uma vez que ela é formada somente por quadradinhos pintados inteiramente ou pela metade.

No intuito de preservar a identidade dos participantes desta pesquisa, os nomes aqui apresentados serão substituídos pelas siglas FP (futuros professores) e um número conforme a quantidade de participantes.

\section{Discussão dos resultados}

Analisando os resultados, foi possível perceber, na resposta à primeira questão, que a maior parte dos professores não tinha experiência na docência. Dos 25 futuros professores (FP) somente 5 já lecionavam, 3 deles para o ensino fundamental (FP13, FP18 e FP25) e 2 para a Educação Infantil (FP14 e FP19).

Sobre as lembranças relacionadas ao ensino de área e perímetro no Ensino Fundamental, 10 professores declararam ter uma lembrança bastante vaga, mas não citaram nada (FP1, FP3, FP10, FP11, FP12, FP14, FP15, FP18 e FP22) e 3 deixaram em branco a questão (FP2, $\mathrm{FP}_{4}$ e $\left.\mathrm{FP}_{5}\right)$.

Dos que declararam as lembranças, 2 indicaram explicitamente serem positivas:

a) Gostava muito (FP16)

Lembranças boas (FP25)

Outros 3 indicaram os procedimentos metodológicos de seus professores:

Metodologias, atividades, vídeos, pesquisas, jogos, projetos. (FP21)

Fazia aulas fora na quadra, média a quadra, a sala de aula. (FP20)

Minha maior lembrança são os alunos deitados no chão para ver quantas crianças eram necessárias para mensurar o perímetro da sala de aula. (FP17) 
É possível notar que, mesmo não declarando ser boa a lembrança, os 3 professores descreveram metodologias de ensino nas quais a participação do aluno era ativa. Entretanto, outros 3 futuros professores lembravam-se da utilização de fórmulas

Me lembro que, para calcular a área, se multiplica a base x altura e para calcular o perímetro, basta somar todos os lados (FP6)

Que para obter o perímetro tem que somar os lados e a área é a base vezes a altura (FP8)

Área: base x altura, perímetro: soma dos lados (FP9)

É possível notar que os esses 3 participantes citaram a fórmula de área do retângulo, possivelmente porque foi por meio dessa fórmula que a temática foi introduzida. Analisando o ocorrido, também é possível observar que os professores só se referiram a perímetro de figuras planas.

Nesse ponto, lembramos que os resultados aqui encontrados se aproximam dos de Garcia Silva, Lopes Galvão e Campos (2013). Essas autoras investigaram a compreensão de 33 professoras que lecionavam para os Anos Iniciais a respeito dos termos “área”, "perímetro" e "superfície" também constataram que "[...] "O perímetro é relacionado, por um bom número de professores, à "medida do contorno" (GARCIA SILVA; LOPES GALVÃO; CAMPOS, 2013, p. 5679). Assim como na nossa pesquisa, Sampaio Figueiredo (2015) e Chiummo (1998) também observaram o reconhecimento da fórmula de área, sobretudo, do retângulo tanto pelos futuros professores e professores atuantes. Chiummo (1998) constatou a existência de um grupo de professores em exercício cuja prática pedagógica esteve focada no processo de "memorização da fórmula do cálculo da área e do perímetro", durante o processo formativo, e, segundo esse pesquisador, tal metodologia se refletia também na forma como procediam os cálculos. Todavia, esses professores investigados pela autora pareciam não compreender o significado dos resultados dos cálculos efetuados.

Nas demais respostas, observamos que as recordações não são muito boas:

Sempre demorei para começar a aprender o conteúdo (FP21)

Nunca fui muito boa em matemática, tanto que fiz reforço (FP7)

Eu só lembro que minha professora retomava a tabuada toda semana o que me deixava muito nervosa, fez com que eu decorasse, mas não aprendesse de fato (FP23)

Bom, perímetro nos anos iniciais foi com dificuldades, mas com um bom aprendizado (FP19)

Nota-se que, embora a questão fizesse menção às lembranças que o futuro professor tem sobre o ensino de área e perímetro nos anos iniciais do Ensino Fundamental, esses 4 professores não esclareceram que tipo de dificuldade encontraram ao estudar a temática, mas parece estar claro que reconheciam suas limitações. 
A análise realizada até aqui nos remete ao trabalho de Tardif (2000). Seu estudo discute os saberes temporais e institucionais do professor, referindo-se aos conhecimentos adquiridos durante a trajetória deste profissional como aluno, desde sua infância, e àqueles adquiridos em sua formação profissional inicial. Nesse sentido, ao observarmos o que esse grupo investigado respondeu sobre suas lembranças acerca do ensino de área e perímetro de figuras planas, vemos indícios de que poucos tiveram experiências mais ativas, parecendo-nos que esses licenciandos, em sua maioria, têm como modelo o ensino da temática focado nos procedimentos de cálculo (predominantemente ligados à formula de área do retângulo).

Para identificar a compreensão dos futuros professores a respeito do que vem a ser área de figuras planas questionamos se quando estivessem lecionando para o $5^{\circ}$ ano do Ensino Fundamental, um de seus alunos perguntasse o que é área de uma figura, o que eles responderiam.

De imediato detectamos que nenhum deles apontou área como a medida da superfície, mas 5 licenciandos apresentaram uma resposta informal referindo-se ao espaço interno da figura, relacionando a área ao seu preenchimento. Foi possível perceber que as respostas dos participantes mostraram haver convergência com as respostas dadas a outras questões, ou seja, a concepção de área ligada à fórmula ou aos procedimentos de cálculo era muito forte. Percebeu-se a preocupação com a reprodução de fórmulas matemáticas.

Analisando o instrumento de pesquisa, também foi possível detectar que 10 futuros professores diriam ao aluno fictício que área é base vezes a altura, no entanto notamos que nenhum dos participantes fazia menção ao fato de que essa era a fórmula de área do retângulo. Outro futuro professor relacionou, informalmente, a medida da superfície, mas relacionou também a fórmula da área do retângulo: "área é um espaço dentro do comprimento e largura, por exemplo, dentro das 4 paredes de uma sala se tem uma área que fazendo uma conta descobre o valor" (FP11). Outro participante teve a mesma referência, mas respondeu de forma equivocada: "São medidas de todos os lados fazendo conta de vezes" (FP13).

Os 7 futuros professores restantes expuseram suas limitações: 5 deixaram em branco e 2 afirmaram não saber. Dentre eles, o FP7 respondeu: "Não sei. Precisaria ir atrás de relembrar o conteúdo".

As informações até aqui analisadas reiteraram que a concepção dos futuros professores investigados está muito ligada somente aos procedimentos de cálculo. Sob o ponto de vista de Ball, Thames e Phelps (2008), limitações observadas no domínio do conceito de área implicariam igualmente em limitações na base de conhecimento desses futuros professores para ensinar essa temática.

A última questão analisada dizia respeito ao cálculo da área de figuras desenhadas em malha quadriculada feito pelos futuros professores. Observamos que a maioria - 12 deles ISSN 2526-2882

$$
42 *
$$


entregaram todas as alternativas dessa questão em branco (FP2, $\mathrm{FP}_{3}, \mathrm{FP}_{4}, \mathrm{FP}_{5}, \mathrm{FP} 7, \mathrm{FP} 15$, FP16, FP18, FP19, FP20, FP21 e FP22) e outro (FP12) - Figura 4 - explicita sua insegurança ao registrar que precisaria "ver um exemplo para ...fazer".

Figura 4 - Resposta à questão apresentada pelo FP12

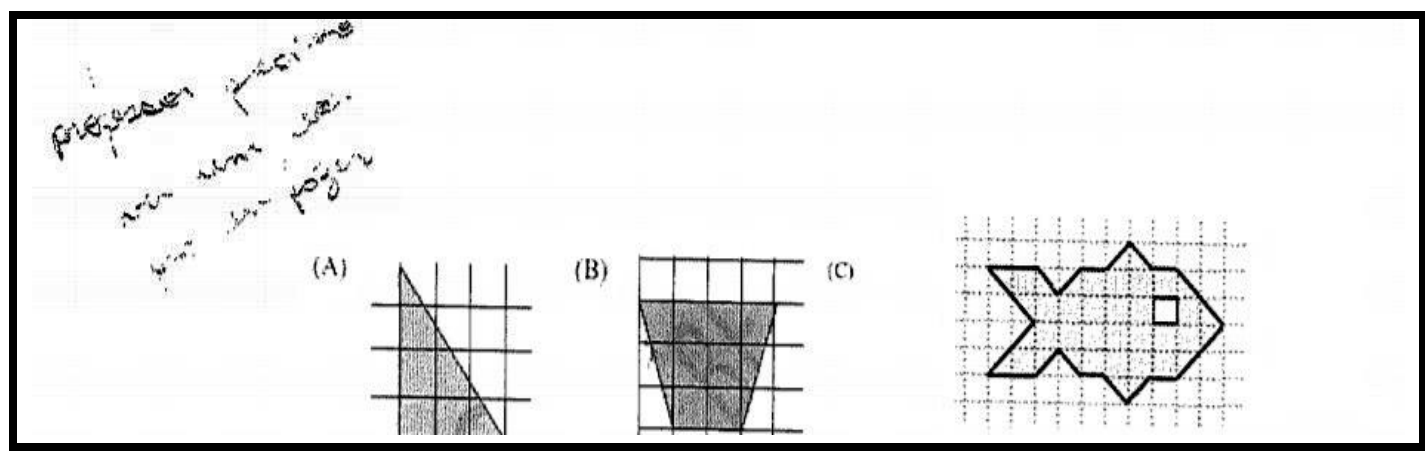

Fonte: os autores

Diante de tal constatação, entendemos que lacunas acerca desse conhecimento ficaram evidentes. A insegurança em responder às atividades pode ser causada pelo fato de não dominarem tais conteúdos e pode ainda levá-los a evitar o ensino de temas que não dominam (CURI, 2004).

Quanto à área do triângulo, foi possível perceber que 8 futuros professores responderam 6 para a área do triângulo e um respondeu 6ua (FP25). Observamos que somente esse estudante mostrou preocupação com a unidade de medida, como podemos verificar na Figura 5 a seguir.

Figura 5 - Resposta à área do triângulo apresentada pelo FP11 e FP25

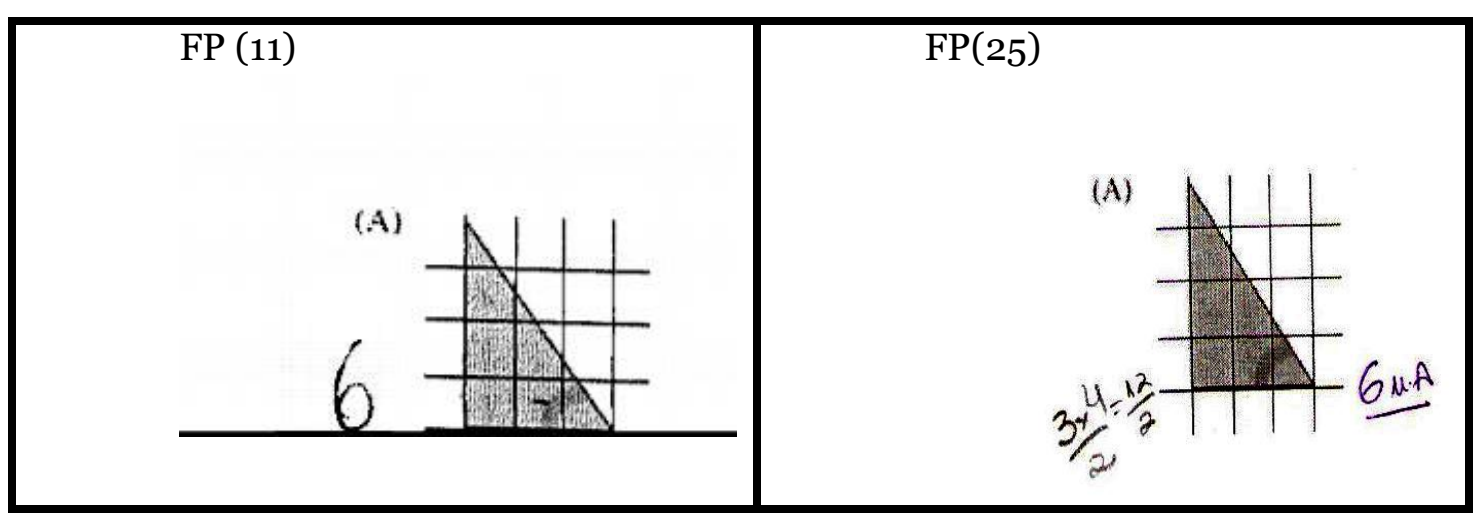

Fonte: os autores 
Garcia Silva, Lopes Galvão e Campos (2013) também encontraram professores atuantes que não apresentaram a unidade de medida quando calcularam área em malha quadriculada.

Quanto à estratégia utilizada, 3 participantes não indicaram nenhuma operação: FP17, FP21 e FP23, já outros 4 licenciandos parecem ter utilizado a contagem, deles, um explicitou tal estratégia FP(11) - Figura 6.

Figura 6 - Descrição da estratégia de contagem apresentado pelo FP1

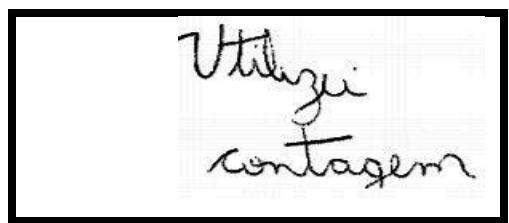

Fonte: os autores

Os outros 5 participantes registraram uma operação: FP1, FP13 e FP14 indicaram a operação 3 x 2 = 6 enquanto FP6 e FP25 registraram o cálculo fundamentados na fórmula de área do triângulo. Na Figura 7, exemplificamos essas respostas.

Figura 7 - Resposta à área do triângulo apresentada pelo FP(13) e FP(6)

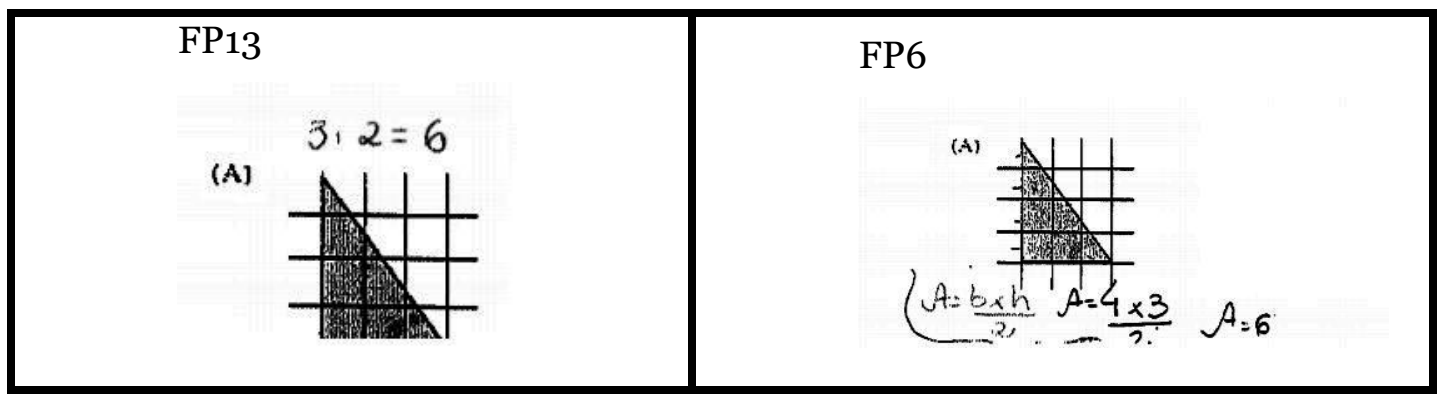

Fonte: os autores

Dos futuros professores que registraram cálculos, podemos inferir que FP6 e FP25 sabiam a fórmula de área do triângulo, mas não podemos afirmar o mesmo acerca do conhecimento dos outros 3 licenciandos (FP1, FP13 e FP14).

Os três últimos futuros professores indicaram 12 como área do triângulo (FP8, FP9 e FP10), isso nos dá indícios de que esses participantes podem ter utilizado aqui de forma equivocada a fórmula de área do retângulo. 
Figura 8 - Estratégia utilizada por FP(9) e a resposta dada por ela para o conceito de área

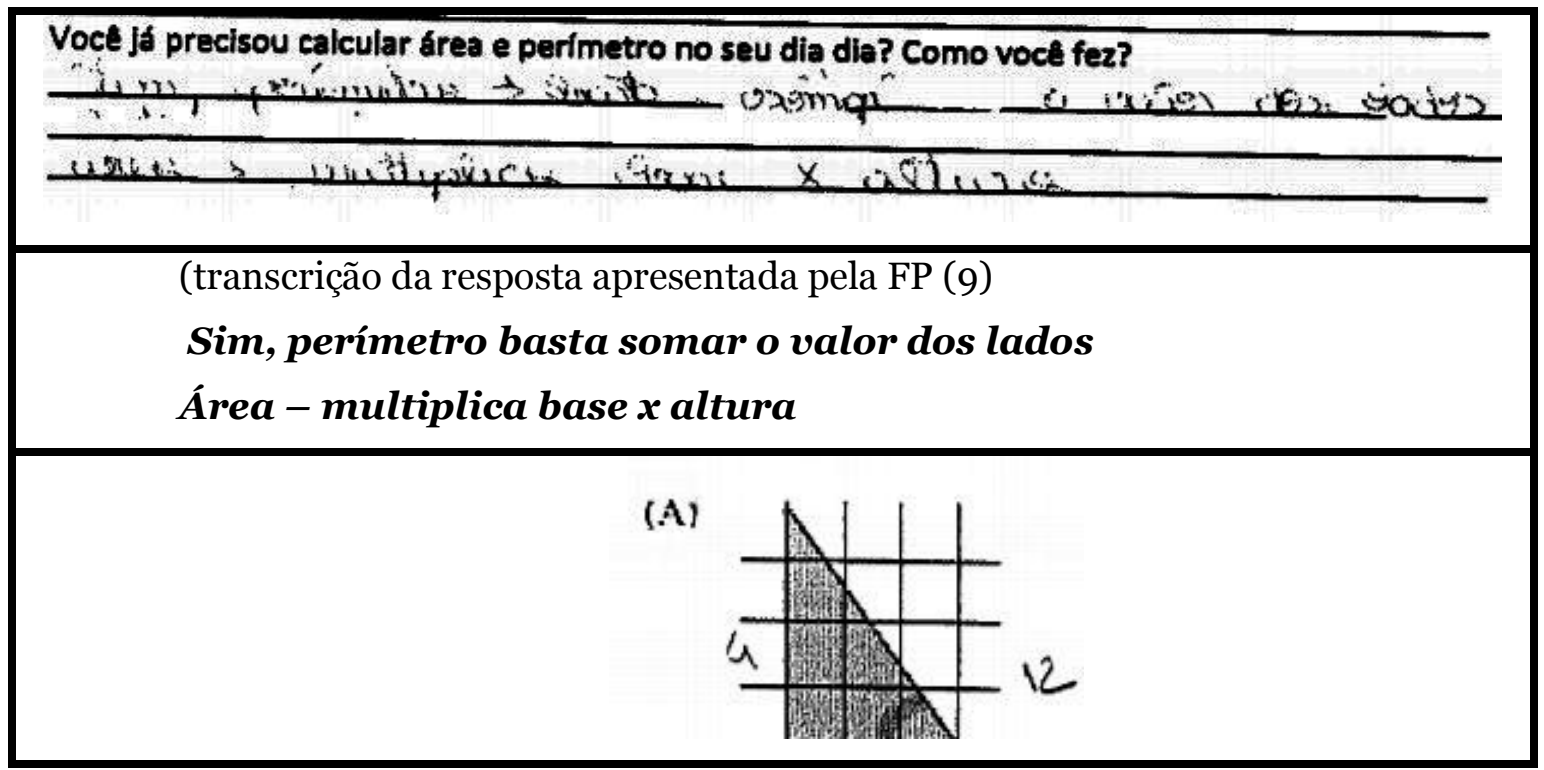

Fonte: os autores

Percebemos que, para esse futuro professor, essa medida está ligada somente à fórmula do cálculo da área do retângulo. Nos dados, observamos que o mesmo ocorreu com o FP9.

Concernente à área do trapézio, observamos 3 licenciandos que indicaram 12 (FP8, FP9 e FP10), possivelmente por considerar a área retangular na qual o trapézio está inserido. No quadro a seguir, observamos que o FP(9) dá indícios de que também utiliza a fórmula do retângulo para o cálculo da área tanto do trapézio como do retângulo, uma vez que registra o valor da altura das duas figuras e a área total.

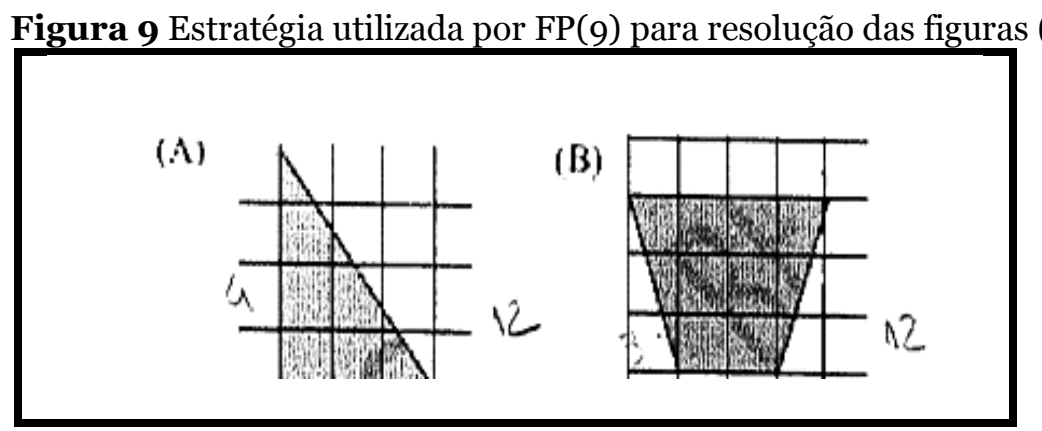

Fonte: os autores

Além desses 3 futuros professores, consideramos que outros 4 (FP11, FP13, FP14 e FP17) podem ter se utilizado da compensação empírica (ou composição/decomposição) para deduzir que a área dessa figura é equivalente a um retângulo 3×3. Desses licenciandos, 2 ISSN 2526-2882 
indicaram 9 como área (FP11 e FP17), 2 registraram a operação 3 × $3=9$ (FP 13 e 14) e os outros registraram somente o 9 .

Figura 10 - Resposta à área do trapézio apresentada por FP13 e FP11

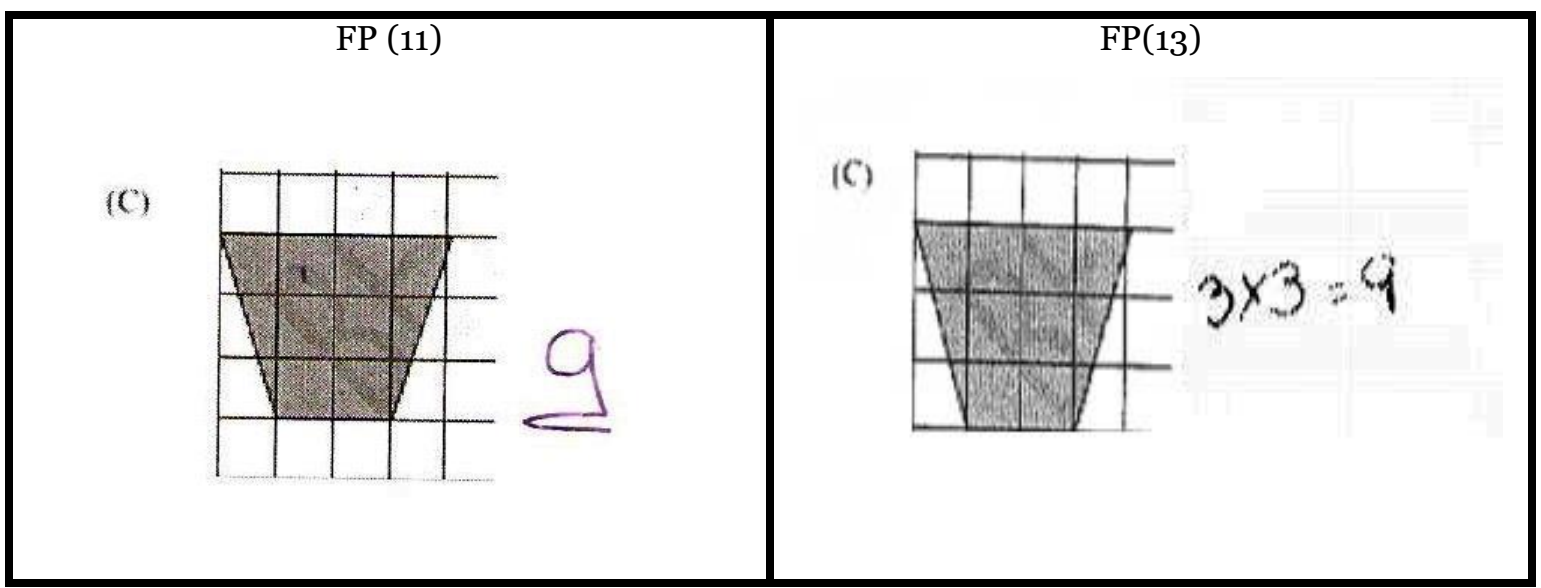

Fonte: os autores

Além do 9, outros valores foram representados: 3 licenciandos indicaram 3 (FP21, FP23 e FP25) e 1 deles (FP25) representou a operação $\frac{4+2}{2}=\frac{6}{2}=3$, nos dando indícios de que possivelmente fez confusão com a fórmula da área do trapézio, esse mesmo professor indicou 3ua. Além dessas respostas, dois indicaram o número 6 (FP1 e FP6).

Figura 11 - Resposta à área do trapézio apresentada por FP(6) e FP (25)

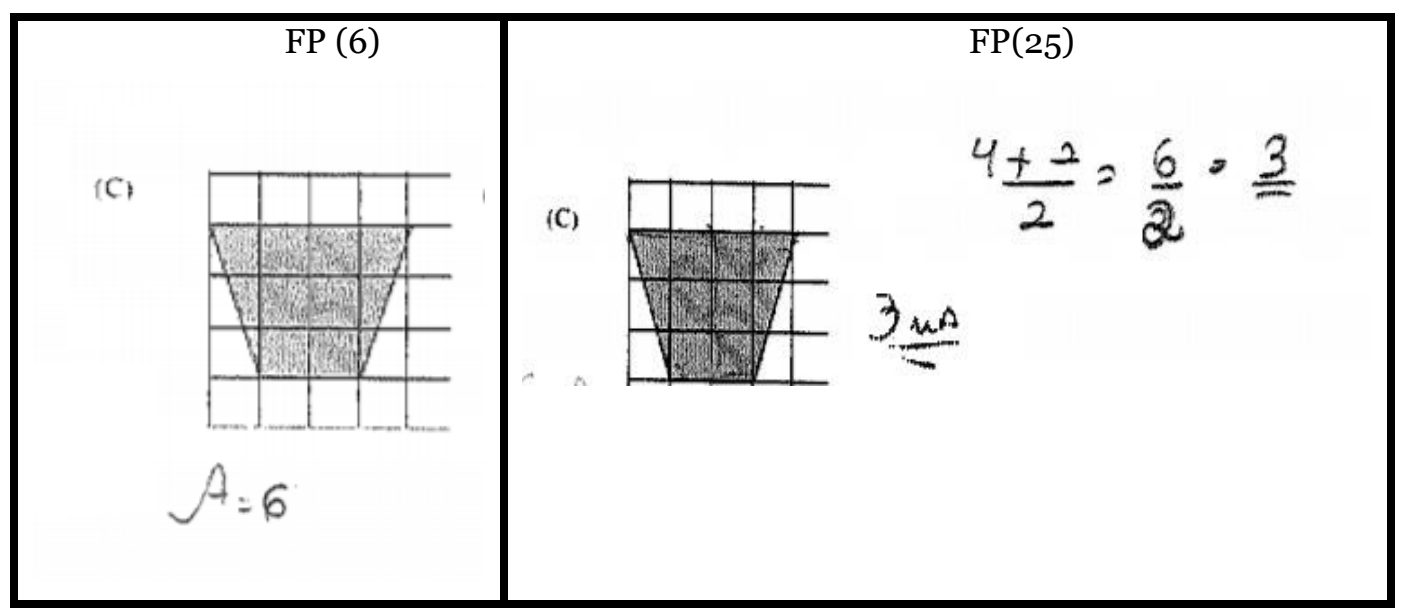

Fonte: os autores

Analisando o ocorrido, é possível perceber que o FP6 pode ter se utilizado também da fórmula de área do retângulo e ter considerado a base com medida 2 uc e a altura 3 uc. O FP(25) 
parece ter se equivocado ao tentar utilizar a fórmula da área do trapézio, pois não multiplicou a soma das bases pela altura.

Observando o cálculo da área dos dois polígonos, é possível detectar que o grupo de professores encontrou mais dificuldades em calcular a medida da área do trapézio equilátero, vale ressaltar que considerávamos que o fato do trapézio ser equilátero, poderia favorecer utilização da estratégia de decomposição/composição.

No que se refere à área da figura $\mathrm{C}$ (peixinho), observamos que o índice de acerto foi mais baixo ainda, somente 2 procederam corretamente a contagem de 31 quadradinhos.

Figura 12 - Estratégia utilizada por FP11 e FP17 para as figuras (C)

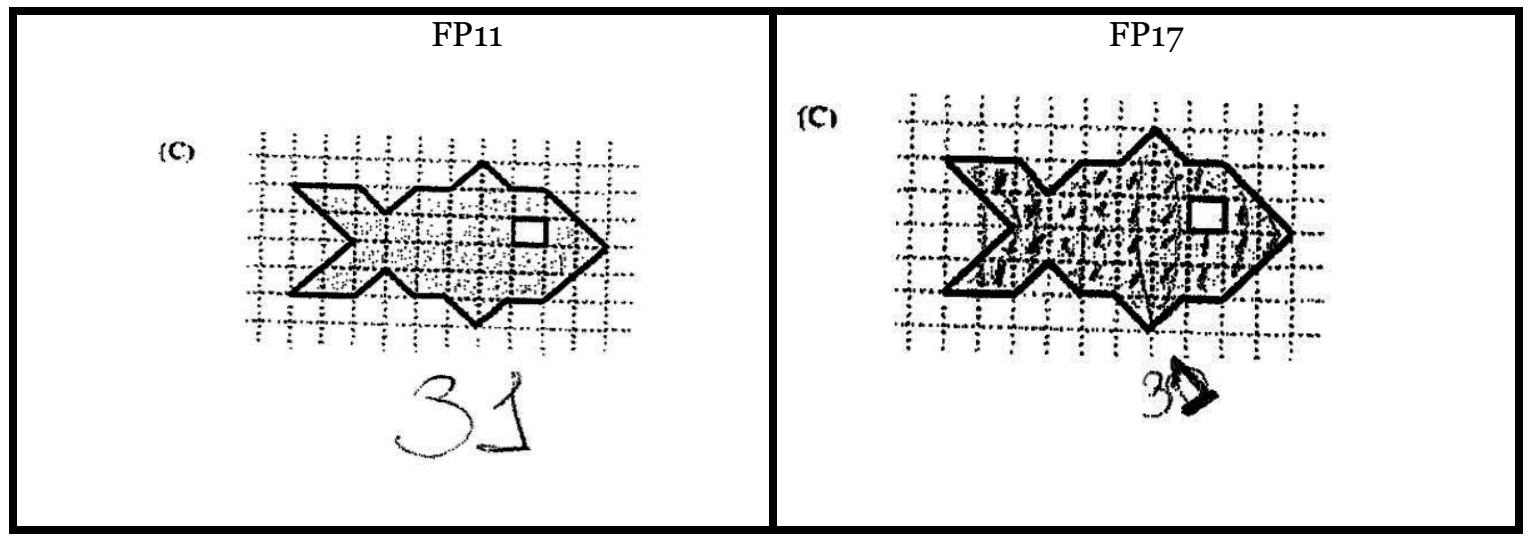

Fonte: os autores

Os 2 participantes deixaram indícios de que utilizaram a contagem: FP11, conforme já relatado, deixou registrado que a utilizou para resolver essa questão e FP17 deixou marcas evidenciando a estratégia utilizada. Outros dois participantes (FP13 e FP14) parecem ter esquecido de "descontar" um quadrado branco presente no interior da figura.

Figura 13 - Estratégia utilizada por FP (13 e 14) para as figuras (C)

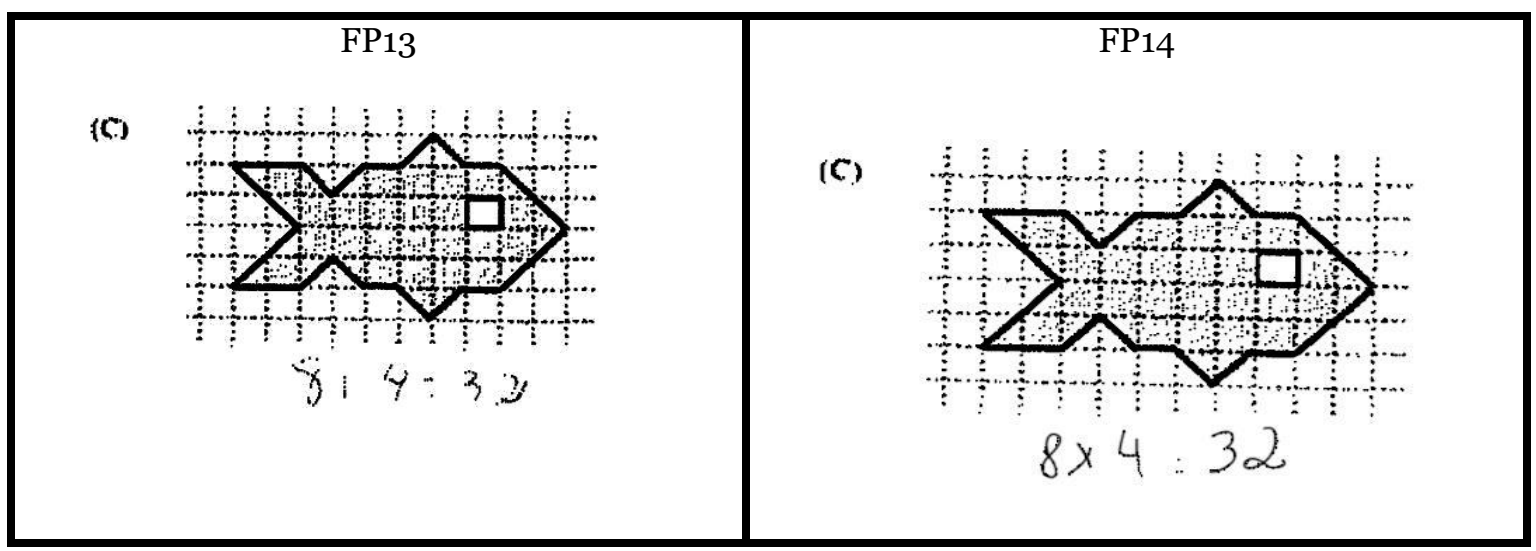

Fonte: os autores

ISSN 2526-2882

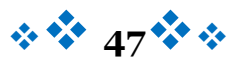


É possível perceber que esses dois licenciandos recompuseram a figura para formar um retângulo com comprimento 8uc, e 4uc e indicaram 32, desconsiderando o registro da unidade de medida e uma unidade de área que precisava ser descontada. Provavelmente, seguindo a mesma linha, $\mathrm{FP}(1)$ respondeu 28 como o resultado da operação 4 x 7 .

Figura 14 - Estratégia utilizada por FP(1) para a figura (C)

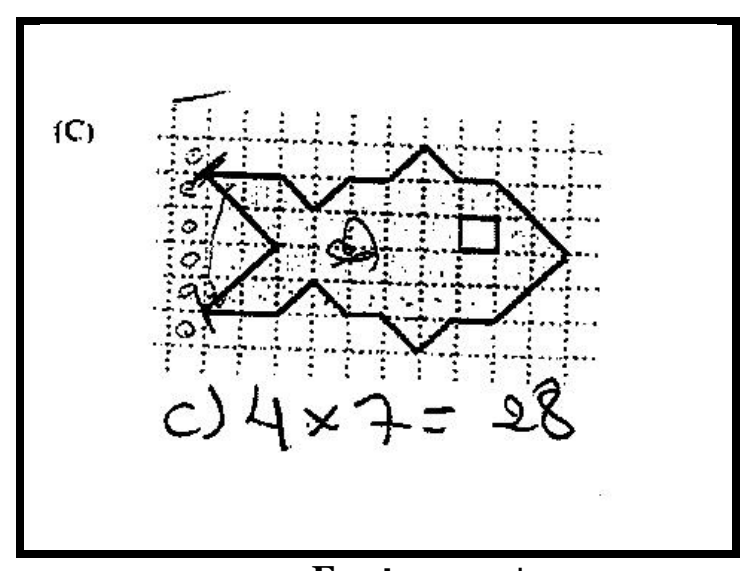

Fonte: os autores

Analisando os cálculos para o item (C) analisado até aqui, observamos que esses 5 participantes utilizaram-se de duas: estratégias a contagem e a recomposição. Além dessas respostas, 3 participantes (FP8, FP9 e FP10) responderam 7, mas um deles registrou a operação $1 \times 7=7$, possivelmente só recompuseram e contaram, equivocadamente, $o$ comprimento. Finalmente, foi possível identificar que 4 licenciandos deixaram esse item em branco (FP6, FP24, FP23 e FP25).

Ao relacionar essa questão com as analisadas anteriormente, é possível observar algumas convergências relacionadas às estratégias utilizadas pelo grupo, se por um lado observamos que parece não ser de conhecimento do grupo a fórmula do trapézio, por outro é perceptível uma tendência dos participantes em considerar a área "base vezes altura", seja utilizando contagem ou recomposição. Kamii e Kysh (2006), apoiadas em Martin e Strutchens (2000), discutem que o conceito de área é:

(...) muitas vezes difícil para a compreensão dos alunos [referindo-se a alunos do Ensino Fundamental], talvez devido a suas experiências iniciais em que é amarrado a uma fórmula (Tal como área = comprimento $\mathrm{x}$ largura) em vez de atividades mais conceituais, como a contagem do número de unidades quadradas que seria necessário para cobrir uma superfície. (KAMII e KYSH, 2006, pp.107-108 ).

Todavia, nesta investigação, notamos que o cálculo de área não foi compreendido em sua amplitude pela totalidade dos futuros professores investigados. Alguns estudantes 
pareciam ficar inseguros ao utilizarem a contagem ou mesmo a composição e decomposição das figuras. Consideramos, assim como Clements e Stephan (2004), que a compreensão do conceito de área é complexo e envolve, dentre outras ideias matemáticas, a compreensão do significado de medida. Dessa forma, ao analisar os conhecimentos explicitados pelos futuros professores concluímos ser de fundamental importância (re)construir com esse grupo a ideia de unidades de medição, ou seja, da escolha de uma região bidimensional adequada como unidade.

Além disso, parece não estar claro também se todos os integrantes dessa turma compreendiam o que vem a ser equivalência de áreas. Nesse sentido, torna-se relevante apresentar vivências que possibilitem a percepção de que regiões congruentes têm áreas iguais. Outra questão a ser desenvolvida seria o entendimento de que o cálculo da área se dá por meio também da compreensão de que a área da união de duas regiões é a soma das áreas e também mostrar a composição e decomposição de regiões como uma boa ferramenta de cálculo e aproveitar dessa estratégia para justificar as fórmulas de área de polígonos.

\section{Considerações Finais}

Observamos que há relação entre as experiências escolares vivenciadas pelos licenciandos e as dificuldades apresentadas, que as poucas respostas sobre as lembranças, relacionadas ao conteúdo de área e perímetro, deixaram claro que os futuros professores poderiam apresentar dificuldades ao responderem o questionário.

Algumas confusões nos permitiram inferir que os futuros professores apresentaram um conhecimento comum do conteúdo ainda insatisfatório, principalmente quando identificamos erros ao definirem ou calcularem a área. Esse conhecimento é essencial para que, ao trabalhar em sala com os alunos, possam avaliar a qualidade dos materiais didáticos (BALL; THAMES; PHELPS, 2008).

Em decorrência das dificuldades com o conhecimento comum do conteúdo, notamos que o conhecimento especializado do conteúdo, também nos pareceu ser limitado. Dessa forma, acreditamos que os futuros professores investigados no momento em que os dados foram coletados ainda não estavam preparados para ensinar área de figuras planas. Foi possível detectar que os participantes precisam ter espaço de estudo e de discussão acerca das ideias matemáticas presentes nessa temática para que pudessem refletir sobre os procedimentos metodológicos a serem utilizados no ensino. Acreditamos que, além disso, o contato com resultados de pesquisa como os de Kamii e Kysh (2006) e Clements e Stephan (2004) e Pessoa (2010), poderiam ajudá-los a refletir sobre o ensino.

Durante a formação inicial desses estudantes, ainda em andamento, acreditamos ser necessárias discussões pedagógicas por meio da realização de experimentos que partam de 
referenciais importantes, como a ideia de medir, por exemplo, para que possam ampliar a sua compreensão matemática. É preciso prover ações que orientem o desenvolvimento dos domínios de conhecimento matemático desses futuros professores por meio de vivencias e contatos com resultados de pesquisa da área. Além disso, a proposição de debates sobre episódios de ensino e a resolução de problemas podem enriquecer tal processo formativo, todavia cabe lembrar que para tanto é preciso que se amplie o espaço para discussão sobre o ensino da Matemática nas grades curriculares.

\section{Referências}

BALL, D. L.; THAMES, M. H.; PHELPS, G. C.. Content knowledge for teaching: what makes it special? Journal of Teacher Education, v. 59, n. 5, nov. 2008.

BRASIL. Secretaria de Ensino Fundamental. Parâmetros curriculares nacionais. Brasília: MEC, 1997.

BRASIL. MEC. Resolução CNE/CP no 1, de 15 de maio de 2oo6. Institui Diretrizes Curriculares Nacionais para o Curso de Graduação em Pedagogia, licenciatura. 2006. Disponível em:< https://goo.gl/gF6bsu >. Acesso em: 12 jan. 2018.

CHIUMMO, A. O conceito de área de figuras planas: capacitação para professores do ensino fundamental. 1998. Dissertação (Mestrado em ensino da Matemática) Programa de Estudos Pós-Graduados em Educação Matemática, Pontifícia Universidade Católica de São Paulo, São Paulo, 1998.

CLEMENTS, D. H.; STEPHAN, M. Measurement in pre-K to grade 2 mathematics. In: CLEMENTS, D. H.; SARAMA, J. (Eds.). Engaging young children in mathematics. Mahwah: Lawrence Erlbaum Associates, 2004. p. 299-317.

CURI, E. A formação matemática de professores dos anos iniciais do ensino fundamental face às novas demandas brasileiras. Revista Iberoamericana de educación, v. 37, n . 4, p. 1-9, 2006. Disponível em: <http://www.rieoei.org/deloslectores/1117 Curi.pdf >. Acesso em: 12 jan. 2012.

Formação de professores polivalentes: uma análise de conhecimentos para ensinar Matemática e de crenças e atitudes que interferem na constituição desses conhecimentos. 2004. Tese (Doutorado em Educação Matemática) - Pontifícia Universidade Católica de São Paulo, São Paulo, 2004.

KAMII, C.; KYSH, J. The difficulty of "length×width": Is a square the unit of measurement? Journal of Mathematical Behavior, v.25, p. 105-115, 2006.

GARCIA SILVA, A. da F.; GALVÃO, E. E. L.; CAMPOS, T. M. M.. Uma interpretação das estratégias utilizadas por um grupo de professores ao calcular área de 
polígonos em malha quadriculada. Actas del VII CIBEM ISSN, v. 2301, n. 0797, p. 5674, 2013.

GATTI, B.. Formação de professores: condições e problemas atuais. Revista Brasileira de Formação de Professores, v. 1, n. 1, maio 2009.

MANDARINO, M. C. F. Que conteúdos da Matemática escolar professores dos anos iniciais do Ensino Fundamental priorizam? In: ENCONTRO NACIONAL DE EDUCAÇÃO MATEMÁTICA, 9., 2013, Curitiba. Anais... Curitiba: PUCPR, 2013. CD ROM

PESSOA, G. da S. Um estudo diagnóstico sobre o cálculo de área de figuras planas na malha quadriculada: influência de algumas variáveis. 2010. Dissertação (Programa de Pós-Graduação em Educação Matemática e Tecnologia) - Universidade Federal de Pernambuco, Recife, 2010.

SAMPAIO FIGUEIREDO, H. R. Investigações a respeito das habilidades matemáticas de licenciandos em pedagogia na modalidade a distância. 2015. Tese (Doutorado em Educação para a Ciência e a Matemática) - Centro de Ciências Exatas, Universidade Estadual de Maringá, Maringá, 2015.

TARDIF, M. Saberes profissionais dos professores e conhecimentos universitários: elementos para uma epistemologia da prática profissional dos professores e suas consequências em relação à formação para o magistério. Belo Horizonte. Revista Brasileira de Educação, n.13, p.5-24, 2000.

\section{Biografia Resumida}

Angélica da Fontoura Garcia Silva: É doutora em Educação Matemática pela Pontifícia Universidade Católica de São Paulo (PUC - SP). Mestre em Educação Política e Sociedade pela Pontifícia Universidade Católica de São Paulo (PUC - SP). Docente do curso de Pós-Graduação em Educação Matemática pela Universidade Anhanguera de São Paulo - UNIAN, na linha de pesquisa: Formação de Professores, Currículo e História.

Link Lattes: http://Link Lattes.cnpq.br/5279665144777466

e-mail: angelicafontoura@anhanguera.com

Helenara Regina Sampaio Figueiredo: É doutora em Educação para a Ciência e a Matemática pela Universidade Estadual de Maringá (UEM - PR). Mestre em Ensino de Ciências e Educação ISSN 2526-2882 
Matemática pela Universidade Estadual de Londrina (UEL - PR). Docente do curso de Pós-Graduação em Metodologias para o Ensino de Linguagens e suas Tecnologias da Unopar, na linha de pesquisa: Formação de Professores e ação docente em situações de ensino.

Link Lattes: http://Link Lattes.cnpq.br/6619487794197361 e-mail: helenara@kroton.com.br 